\title{
Vorwort zur achtzehnten Auflage
}

In der 17. Auflage hatten das VerkSichG und der neue Wortlaut des KFG (mit der neuen Benennung als StVG) nur im Nachtrag gebracht werden können; dort war auch das neue GüKG aufgenommen worden; in der vorliegenden Auflage ist das VerSichG in das Buch selbst eingearbeitet worden. Anhang 11 enthält im Zusammenhang den ganzen Wortlaut des VerkSichG, die Erläuterungen finden sich an den einschlägigen Stellen des Buches; so ist die Entziehung der Fahrerlaubnis einheitlich bei $\S 4 \mathrm{StVG}$ behandelt, auch soweit sie durch das Gericht ( $\$ 42 \mathrm{~m} \mathrm{StGB}$ ), ggf vorläufig ( $\$ 111 \mathrm{a}$ StPO) erfolgt. - Das GüKG ist, ausführlich erläutert, im Anhang 5 an die Stelle seines Vorläufers getreten. - Anhang 1 bringt die AusbildV in neuer Fassung, Anhang 4 die Neufassung der BOStrab, Anhang 9 die der GebührenO, Anhang 2 das neue BundesfernstraßenG. -- Anhang 19, Technik, ist als selbständiger Teil fortgefallen; sein Inhalt ist an den einschlägigen Stellen des Buches eingearbeitet worden. - Die KfzTeileVerordnung (30. 7. 53) findet sich bei $\S 22$ StVZO.

Wesentliche Teile des Buches erscheinen in großem Umfang in ganz neuer Darstellung. Die Anderungen der Verkehrs- und der ZulassungsO v 24. 8. 53 haben mit ihrem ungewöhnlich hohen Ausmaß fast alle Teile des Buches beeinflußt. In der StVO sind neu die $\S \S 3 \mathrm{a}$ und $31 \mathrm{a}$. - Auch die StVZO bringt manches Neue, $\S \S 15 \mathrm{a}-\mathrm{c}, 32 \mathrm{a}, 57 \mathrm{a}, 64 \mathrm{a}, 73,74$, ferner gründliche Änderungen, darunter begrüßenswerte Verbesserungen, namentlich in der Systematik, $\mathrm{zB}$ in der (fast restlosen) Zusammenfassung der Beleuchtungsvorschriften in der StVZO; die Kommentierung hat an ihre Spitze (S $608 \mathrm{ff}$ ) eine Ubersicht über die nicht leicht zu überschauenden Einzelregelungen gestellt.

Im StVG mußten die $\S \S 4,6$ und 27 ganz umgestaltet werden, in welchem Umfang, erkennt man zB daran, daß die Erläuterung des $\S 4$ von 12 auf 19 Seiten, des $\S 27$ von $2^{1 / 2}$ auf $14^{1 / 2}$ Seiten angewachsen ist. Die Anderung der Rechtslage der Kleinkrafträder und der der Fahrräder mit Hilfsmotor hat ferner Umarbeitung einer schwer vorstellbaren Zahl von Stellen des Buches erfordert. § 6 StVG bringt rechtssystematisch tiefgreifende Neuerungen, Gesichtspunkte, die sich insb auch auf $§ 4$ StVO auswirken.

Wo nach dem Kriege die obergerichtliche Rspr die frühere bestätigt hat, konnte zugunsten jener auf die Anführung dieser zT verzichtet werden; notfalls müssen frühere Auflagen herangezogen werden. Für die neue Auflage sind mehr als 550 Obergerichtsurteile verwertet worden.

Die Rechtsentwicklung hat einen gewissen Abschluß erreicht; da liegt ein Rückblick auf den Werdegang dieses Buches nahe, der die wachsende Bedeutung des Straßenverkehrsrechts widerspiegelt. Die 1. Auflage (1926) hatte in kleinem Format 777 Seiten, die neue hat, - trotz Formatvergrößerung schon bei der 16. und trotz vielfacher Verwendung kleineren Druckes - nun 1254 Seiten; kennzeichnend ist auch das Anwachsen der Zahl 
der Hauptstichwörter des Registers von 835 (1926) auf 2472 - nicht gerechnet die erhebliche Vermehrung ihrer jeweiligen Unterabteilungen -. Die Umbenennung des KFG in StVG hat an - übrigens nicht rein schematischer Arbeit des Umstellens von "KFG" in "StVG" mehr als 850 Änderungen erfordert.

Wie schon im Vorwort zur 17. Aufl im Hinblick auf kritische Bemerkungen zur 16. ausgeführt, macht die Dauer der Drucklegung eines umfangreichen Buches es meist unmöglich, daB die neue Auflage beim Erscheinen dem augenblicklichen Stand von Gesetzeslage und Rspr entspricht. Die Hervorhebung der gleichen Bemängelung auch wieder zur 17. bei deren kritischen Beurteilung gewinnt durch Wiederholung nicht an Berechtigung.

Der Umfang der Rspr über Verkehrsflucht und Alkoholmißbrauch ist besonders beschämend bei einem Volk, dem man früher einen hohen Grad Diszipliniertheit nachrühmte. Tragen die neuen gesetzlichen Vorschriften zur Hebung der Verkehrszucht, zur Stärkung des Verantwortungsbewußtseins bei - und dieses Ziel hat auch ihrer Erläuterung in diesem Buch durch alle Auflagen vorgeschwebt - , so wird man die Hoffnung auf eine Senkung der Unfallzahlen nicht aufzugeben brauchen. 